\title{
Entre o Congresso de Lisboa e a Constituinte brasileira: concepções de Estado do empresário luso-gaúcho Antônio José Gonçalves Chaves
}

Between the Lisbon Congress and the Brazilian Constituent Assembly: Concepts of State of the Portuguese-Gaucho Entrepreneur Antônio José Gonçalves Chaves

Marisa Saenz Leme*

\section{Resumo}

O artigo avalia as concepções de Antônio José Gonçalves Chaves, rico charqueador de origem portuguesa radicado no Rio Grande do Sul, sobre como se daria a organização ideal do Estado, num período de transição entre a afirmação do "Reino-Unido" - em que se pensava a autonomia do lado brasileiro num contexto liberal - e a formação da monarquia constitucional num Brasil praticamente independente, em que se convocara a Assembleia Constituinte. Problematizam-se os seus posicionamentos em face do contexto político da época, observando a sua possível inserção no campo considerado "liberal-radical", a ênfase nas temáticas municipais e provinciais, bem como a articulação entre as suas concepções políticas e socioeconômicas. As fontes primárias do trabalho são as Memórias ecônomo-políticas sobre a administração

\begin{abstract}
This article assesses the concepts of Antônio José Gonçalves Chaves, a wealthy rancher from Portugal based in Rio Grande do Sul, about how would be the ideal state organization during a transitional phase between the "United Kingdom" statement - in which the Brazilian autonomy was contemplated in a liberal context - and the monarchy formation in a country that was almost independent, where the Constituent Assembly is being organized. There is a problematization on his positions, given the political context of that time, and considering his potential integration in what is called the "liberal radical" field, regarding the emphasis in the municipal and provincial issues, as well as the linking between his political and socioeconomic opinions. The primary source of the work is the book Memórias ecônomo-políticas sobre a adminis-
\end{abstract}

\footnotetext{
* Universidade Estadual Paulista Júlio de Mesquita Filho (Unesp), Faculdade de Ciências Humanas e Sociais (FCHS), Departamento de História. Franca, SP, Brasil. msaenzleme@gmail.com
} 
pública do Brasil, publicadas por Chaves entre 1822 e 1823 , em que se analisam a administração colonial, a escravidão, a questão das terras no Brasil e a organização socioeconômica da província do Rio Grande do Sul.

Palavras-chave: liberalismo; províncias; monarquia federativa; municípios. tração pública do Brasil, published by Chaves between 1822 and 1823, going through topics such as colonial administration, slavery, the land issue in Brazil and the socioeconomic structure of Rio Grande do Sul.

Keywords: liberalism; provinces; federative monarchy; municipalities.

\section{UM EMPRESÁRIO LUSO-GAÚCHO ENTRE AS CORTES DA "NAÇÃo" PORTUguesa E A Assembleia Brasílica}

Antônio José Gonçalves Chaves nasceu na vila de Chaves, no último quartel do século XVIII, em Trás-os-Montes, Portugal (Barreto, 1973, p.336). De acordo com Saint-Hilaire, teria vindo para o Rio Grande do Sul como caixeiro. Tratava-se de uma época em que os comerciantes portugueses mandavam vir jovens rapazes de Portugal, a fim de aprenderem o ofício comercial e trabalharem, sem salário, nas suas lojas, onde também ficavam hospedados, com a sua alimentação por conta do proprietário (Gorenstein, 1993). Por esse modo teria chegado Antônio José ao Brasil, provavelmente a Porto Alegre, cidade que se desenvolveu na segunda metade do século XVIII, após a imigração de açorianos para a região (Santos, 1984). Dada a sua própria informação, de que em 1822 estava havia 16 anos no Brasil, deduz-se que aqui chegara em 1806.

$\mathrm{Na}$ época da viagem do botânico francês pela província, entre agosto e setembro de $1820,{ }^{1}$ Chaves possuía casa na cidade do Rio Grande e charqueada junto ao rio Pelotas, onde também tinha residência, sendo considerado um dos "iniciadores" da vila de mesmo nome (Franco, 2004, p.17). ${ }^{2}$ Saint-Hilaire, que aí se hospedara, reputou-o como um "homem culto, sabendo o latim, o francês, com leituras de história natural...” (Saint-Hilaire, 1974, p.67). Informou possuir ele significativa biblioteca.

Interessante observar uma indicação de "modernidade" feita pelo viajante a respeito do seu hospedeiro. Embora em vários aspectos a casa à beira do rio Pelotas fosse "comum em todo o Brasil", distinguia-se por parte do mobiliário: "As cômodas e as secretárias são móveis completamente modernos no Brasil e somente encontradiços em um número exíguo de casas" (Saint-Hilaire, 1974, p.67). De acordo com o francês, Chaves possuía um "iate”. Discorreu ele sobre a riqueza dos charqueadores em geral e a de Chaves em particular, numa região que se expandia: 
Algumas famílias do Rio Grande (cidade) mudaram-se para aqui e é crível que daqui a pouco tempo esta aldeia será acrescida de um grande número de novos habitantes, atraídos pela posição favorável da povoação, da beleza da região e riqueza dos que se acham aqui estabelecidos... Há entre eles homens muito ricos. O Sr. Chaves, por exemplo, que começou como caixeiro, dispõe hoje de uma fortuna avaliada em 600 mil francos. (Saint-Hilaire, 1974, p.69)

Irmanado com os destinos da sua terra de adoção, sentindo-se "impelido de um ardente patriotismo", Gonçalves Chaves publicou, de forma anônima, ${ }^{3}$ em uma única obra, cinco Memórias a respeito de diferentes traços da "administração pública" do Brasil. Duas delas, a primeira, sobre os "capitães generais" - que propunha fossem abolidos - e a segunda, sobre as "Municipalidades, compreendendo a união do Brasil com Portugal”, foram escritas no primeiro semestre de 1821, tratando-se, portanto, de um período em que, na sequência da Revolução do Porto de 1820, vivia-se a implementação do liberalismo, inicialmente, num projeto de união luso-brasileira para, logo a seguir, colocarem-se os feitos da separação (Neves, 2003). A terceira memória, "Escravatura”, fora redigida em 1817, com vistas a ser publicada no Investigador Português, na Inglaterra; contudo, confiada a um "amigo" que, mudando-se para o Rio de Janeiro, prometera remetê-la para o jornal, seu autor não teve mais notícia do seu paradeiro (Chaves, 2004, p.80). A quarta e a quinta memórias foram escritas na sequência das duas primeiras, versando, respectivamente, sobre a questão das terras no Brasil e sobre a situação socioeconômica do Rio Grande de São Pedro. Publicadas as quatro primeiras em 1822, a quinta memória veio a lume em $1823 .{ }^{4}$

A própria trajetória dos caminhos buscados para a publicação das memórias indica as articulações do autor, para além da Capitania/Província em que vivia, bem como as tensões políticas então vivenciadas no país em formação. As duas primeiras memórias, escritas em 1821 - em que se propunham novas formas político-administrativas para o momento vivido - foram enviadas para um "amigo" residente em Salvador que, após longo silêncio, recusou-se a publicá-las, por considerar que em parte continham teor ofensivo à monarquia constitucional portuguesa:

posto em as mesmas Memórias se desenvolvam princípios dignos e mui análogos ao presente sistema pela nação adotado, contudo outros vários se encontram, e mui principalmente para com esta província (Bahia), na qual de dia a dia se desenvolve o espírito público com decidida adesão à causa da pátria comum e ten- 
do pela sua ordem de aqui se publicar, acomodei-me à precisa política de que não saísse à luz doutrina censurada pela opinião dos homens do melhor senso, idêntica à dos que a soberania do Congresso tem condenado como anticonstitucional. (Chaves, 2004, p.80)

Cabe lembrar ter sido a Bahia, logo após o Pará, a segunda província do Brasil a aderir prontamente à Revolução Constitucional do Porto, de 24 de agosto de 1820 , tendo-se na sequência formado junta de governo que, durante os acontecimentos sucedidos no Brasil entre os últimos meses de 1821 e os primeiros de 1822 - envolvendo as ordens do Congresso de Lisboa, a proclamação do Fico e a expulsão do Rio de Janeiro das tropas portuguesas comandadas pelo general Avilez -, manteve-se fiel aos procedimentos emanados da Metrópole (Lima, 1989, p.190ss; Tavares, 1977).

Dessa forma, embora escritas com vistas ao Congresso de Lisboa, ${ }^{5}$ numa concepção integrativa de "nação portuguesa", as memórias foram consideradas em parte incompatíveis com a sua soberania, o que indica a importância nelas auferida à parte brasileira do Reino. Enviou-as então esse "amigo" baiano para outra pessoa (os nomes foram mantidos por Chaves no anonimato), para o Rio de Janeiro, "onde talvez se pense ao inverso desta província”, o que facilitaria a impressão. Essa missiva datou de 22 de abril de 1822.

Contudo, o "amigo" fluminense, embora concordando com o seu teor, considerava que parte da temática estava ultrapassada. Pois, nesse intervalo da viagem dos manuscritos entre Salvador e o Rio de Janeiro, transformara-se grandemente o quadro político interno, com a convocação, por parte do regente d. Pedro, da "Assembleia Brasílica", em 3 de junho de 1822, acontecimento fundamental para o Brasil separar-se de Portugal, ${ }^{6}$ que inverteu o sentido do processo constitucional então em curso, deixando de serem pertinentes as formulações pensadas para a "nação portuguesa" como um todo. A missiva datava de 22 do mesmo mês.

Reenviado o material ao Rio Grande de São Pedro para que Chaves o atualizasse, recusou-se ele a fazê-lo, e o publicou na íntegra, no Rio de Janeiro, na Tipografia Nacional, em 1822,7 com pequenas explicações a respeito desses momentos de transição, em que redirecionou o trabalho para a "Assembleia Geral e Constituinte do Brasil". Levava o título de "Memórias ecônomo-políticas sobre a administração pública do Brasil: compostas no Rio Grande de São Pedro do Sul e offerecidas aos Deputados do mesmo Brasil por HUM PORTUGUEZ residente no Brasil ha 16 anos; que professa viver só do seu trabalho e deseja o bem da Nação, ainda com referência ao seu proprio". Tinha 
por cabeçalho: "Com tudo quanto posso e quanto valho/ De todo o coração à Patria sirvo". O que mostra a extensão do então moderno entendimento de "pátria", vinculado não ao local de nascimento, mas decorrente de uma concepção de direito, da escolha feita por quem vivesse e desenvolvesse seus negócios num determinado lugar (Lyra, 1998).

Com um posicionamento inicialmente a favor da união luso-brasileira, mediante a implementação do liberalismo por intermédio das Cortes de Lisboa - como foi o caso de vários segmentos liberais - Gonçalves Chaves manifestou-se claramente a favor da independência do Brasil, estando presente "ao ato da aclamação de D. Pedro I como imperador constitucional do Brasil, em 12 de outubro de 1822, perante o Senado da Câmara de Rio Grande" (Franco, 2004, p.18). Tratava-se de um contexto de legitimação política do novo império, em que, "ao longo de 1822-1823, as câmaras brasileiras declaravam a sua adesão a D. Pedro e a uma constituição brasileira” (Souza, 1999, p.143).

Durante o $1^{\circ}$ Reinado, o charqueador contribuiu financeiramente com o governo central, e obteve contrato para "o munício das tropas" (Miranda, 2006, p.218). Membro do Conselho Geral da Província, nas Regências elegeu-se para a vereança da primeira câmara municipal de Pelotas, em 1832; em 1835, foi eleito para a Assembleia Provincial. Em época ainda não precisa, entre fins do $1^{\circ}$ Reinado e início das Regências, estabeleceu-se também com charqueada no Uruguai. Numa época em que a economia da província recebia grande impulso urbano-industrial (Berute, 2011), foi pioneiro da navegação a vapor no Rio Grande do Sul.

Faleceu próximo a Montevidéu, vítima de um acidente de barco. Embora não esteja esclarecido o seu envolvimento com a Revolução Farroupilha, são notórios os seus "vínculos afetivos, comerciais e políticos" com Domingos José de Almeida, "então Ministro da Fazenda da república Rio-grandense”. Em carta à esposa, este lamentava a morte de Chaves: "era meu amigo, era virtuoso, e além de tudo temos contas bem complicadas...” (Franco, 2004, p.19).

\section{AUTONOMIA PROVINCIAL E MUNICIPAL}

NA UNIDADE DA “MONARQUIA FEDERATIVA"

Gonçalves Chaves mostrou-se fortemente afinado com as concepções liberais e ilustradas da época, apresentando formulações político-institucionais importantes de se analisarem, visando o conhecimento da ampla gama de posicionamentos que se apresentaram para o país em construção, bastante 
matizados entre si, mesmo em campos aparentemente homogêneos. Nesse diapasão, adquire relevância recuperar a matização do pensamento do autor em apreço, para se avaliar como se poderia inseri-lo entre os segmentos políticos então em evidência.

Na primeira memória, Chaves condenou taxativamente a organização político-administrativa da colônia. Recuperando historicamente a primeira divisão das capitanias, doadas aos "melhores servidores ou grandes senhores do reino", como "proprietários e senhores absolutos", considerou o "sistema" "absurdo", não diferindo do "feudalismo". Na organização ocorrida em sequência, embora superior à primeira, o modo como se delegou poder aos capitães-gerais tornara-os "despóticos".

Atuando eles impunemente, não haveria "ramo nenhum da administração pública em uma capitania, nenhum indivíduo, que não esteja sujeito ao poder absoluto dos capitães-generais” (Chaves, 2004, p.37). Recuperou o autor o histórico da "primeira magistratura com a denominação de capitania-geral", entre os aqueus, e tratou também da Nova Inglaterra e das colônias espanholas, apontando a sua instituição como causa dos fracassos político-administrativos dessas metrópoles. Em decorrência, elogiou o exemplo do Pará e da Bahia, como referido, províncias que prontamente aderiram à Revolução Constitucional do Porto.

Duas capitanias tiveram o valor de arrostar-se a este Colosso de tirania, e ainda que tiveram o descuido de não o enforcar em estátua, tiveram o bom acordo de criar um governo da escolha do povo. Estes governos têm feito a felicidade dos povos, como era de esperar: por toda a parte se assoalham suas bondades, e como os títulos que assumiram são de governos provisórios, clamam todos os mais povos por governos provisórios... (p.42)

Contudo, embora instasse para que as outras capitanias - que reforçava, eram agora províncias - seguissem esse exemplo, alertava para o risco da instabilidade: "E querer-se-á esperar que todas as capitanias se revoltem e que estas revoluções, cujas consequências ninguém é capaz de prever, nos lancem talvez em um abismo de males intermináveis?” (p.42). Para evitar a fragmentação e a anarquia, recomendava aos "nossos deputados" nas Cortes a urgência de se resolver a matéria, posto que "o sistema de governo por capitanias até aqui adotado é conforme o despotismo, homogêneo à tirania e incompatível com um sistema constitucional..." (p.44). A medida visava, portanto, a unidade das províncias, numa nova ordem administrativa. 
Observe-se que a ênfase dada pelo charqueador ao poder do capitão-general não corresponde às avaliações historiográficas sobre o exercício do poder administrativo na Colônia Brasil, uma vez que se acentua a força das câmaras e a debilidade/falta de legitimidade do governador/capitão geral (Russell-Wood, 2014). A visão do autor analisado poderia decorrer da inserção da capitania de São Pedro do Rio Grande na América Portuguesa: de formação colonial recente, nela ainda não se desenvolvera uma sociedade mais apta a se impor ao domínio do capitão-geral, o que se agravaria pelo fato de tratar-se de região de fronteira (Menz, 2009), em contínua disputa com os espanhóis, reforçando o poderio desse dirigente; por fim, a capitania se desenvolvera já sob o domínio da ilustração e da ação pombalina, que procurou impor um modo bem mais centralizado de governo (Gouvêa, 2001).

Em decorrência da crítica à forma de gestão colonial portuguesa, colocava-se a questão de se propor uma nova organização administrativa para o Brasil, inicialmente, na forma do Reino-Unido com Portugal. O que se evidencia na segunda memória, "sobre as municipalidades, compreendendo a união do Brasil com Portugal”.

Em primeiro lugar, importa frisar o modo pelo qual Chaves formulava a questão da monarquia em relação à república. Tendo como pano de fundo o arco de possibilidades político-institucionais daquele momento, ponderava: "Os que mais aferrados estiverem a um sistema federativo, não teremos dúvida nenhuma em provar-lhes que é tão compatível com uma monarquia temperada como com uma república...” (p.68). Em comparação com os Estados Unidos - em que, no seu entendimento, "cada um tem em si a soberania e pode fazer as suas leis políticas e civis" - considerava ser possível se dar o mesmo no Brasil: "somente com a diferença que na Constituição federativa em que se concedesse o direito às diferentes províncias de erigirem-se em estados independentes, se poria a precisa condição que sua forma de governo ao sistema monárquico constitucional seria conforme...” (p.68).

Nessa concepção, igualar-se-iam as condições de um rei e de um presidente republicano, tornando-se a hereditariedade um fator favorável ao Brasil: "nenhuma diferença podemos achar entre um presidente e um rei constitucional como o nosso, a não ser que este goza de uma magistratura hereditária e aquele de uma magistratura eletiva ou amovível, diferença que dá melhoria a nosso favor, porque nunca se oferece questão de quem há de ser o rei ou presidente, porque é a mesma coisa”. Pensamento esse que 2 anos mais tarde seria também claramente formulado por Cipriano Barata, o famoso líder 
"liberal-radical" então sediado no Recife (Sentinella da Liberdade na Guarita de Pernambuco, n.61, 1 nov.1823). ${ }^{8}$

É de se observar, ainda, que a simplista operação de se anular a diferença entre hereditariedade e eleições rotativas poderia decorrer de uma preocupação com a unidade das províncias do Brasil. Dessa forma, Chaves iniciou a segunda memória discorrendo sobre o isolamento e a diversidade das províncias, evidenciando - assim como já o fizera na primeira memória - o seu temor de "revoluções" e "guerra civil". Por sua vez, condenava o fracionamento das Américas Hispânicas:

o mais que podemos fazer é recomendar a todos os povos residentes no Brasil que não se deixem fascinar pelo prospecto lisonjeiro que se lhes apresente nas mudanças dos governos provinciais por via de revoluções... O Brasil é um corpo de Estado mui melindroso, em razão do estado de sua população, para que possa suster-se no sofrimento de alguma guerra civil, sem passar pelas mesmas desgraças das colônias espanholas ... (p.49).

Entendimento esse que já se apresentara em 1817, ao lamentar o autor que as declarações de independência das "províncias hispano-americanas", no curso dos "embaraços e desgraças da sua metrópole", não tivessem contado com uma liderança que expusesse "a sua vida com as únicas miras da salvação pública, e finalmente união nos diferentes povos, e por isso em dez anos de aberta luta não se podem determinar os seus destinos" (p.84).

Nesse quadro de temor à fragmentação, afirmava: "Debaixo da expressão 'União do Brasil com Portugal', entendemos igualmente a 'união do Brasil entre si' e ainda que parece ser tudo a mesma coisa, temos esta como objeto primário e, com relações bem mal determinadas até aqui, o Brasil!” (p.48). Considerava estar o Brasil "mais propínquo a desunir-se entre si do que unir-se a Portugal...” (p.49).

Reiteradamente preocupado com esse isolamento e diversidade, a "esperança” de Chaves residia na combinação da ação legislativa com a instituição monárquica. Assim, já direcionado para a Constituinte brasileira, urgia a "reunião de todos os nossos deputados no Congresso Nacional”, conclamando "todo cidadão bem intencionado" a concorrer "para a efetividade desse acontecimento". Por sua vez, afirmava: "Regulando-nos pela opinião mais dominante - se é que bem a conhecemos -, tomaremos a monarquia constitucional, ou temperada, pela forma de governo mais própria para a nossa união, que nos parece ser, e sem dúvida, a tábua de salvação mais segura" (p.50). 
Num raciocínio em que separava, de modo nada claro, o entendimento de "soberania" - no caso, da nação portuguesa" - da presença do rei, defendia a permanência deste no Brasil, ainda que no contexto da união com Portugal (Capítulo V da segunda memória, "Sobre a capital do Brasil e governo que nela poderá se estabelecer”, p.63-65). No capítulo seguinte, enaltecia a imagem real: "Um rei constitucional, queremos dizer, um rei que respeita os direitos do seu povo, é uma imagem da divindade e o povo lhe tributa adorações em seu coração sem se curvar diante dele” (p.69). Assim como o fizera em 1817, na sua memória sobre a escravidão, em relação à figura de d. João VI - considerando que "a vinda de sua majestade uniu todos os indivíduos, conciliou todos os ânimos, prestou-lhe consideração política...” (p.84) - em 1821 recuperava o mesmo entendimento para o desempenho pedrino.

Mas simultaneamente se colocava em perspectiva contrária à centralização: enunciou, logo de início, a sua não concordância com a Constituição espanhola, dada a centralidade do seu sistema de governo. À moda do conceito clássico de "res publica", vigente na Idade Moderna (Gelderen; Skinner, 2002), Chaves considerava que seus posicionamentos político-institucionais, que abrangiam a monarquia, estavam a serviço daquela: "nós declaramos nossas ideias e bem pagos nos julgaremos se aproveitarem à república” (p.50). No seu entendimento, a soberania residia na "nação" (p.60).

Importa avaliar a organização proposta por Chaves para a instituição da "monarquia federativa" - lembre-se, ainda pensando na união luso-brasileira - em que as "municipalidades", as "Câmaras", constituíram a raiz de todo o seu projeto. Discorrendo sobre a importância dos "conselhos" lusitanos - equivalentes ao senado da câmara colonial -, "quando Portugal era Portugal" (p.55), o charqueador lastimava a sua perda de prestígio após a Restauração e propunha a recuperação da sua força. Tópico que no seu entender comporia a "regeneração" em curso com a Revolução do Porto.

Nesse projeto, as câmaras teriam autonomia para a gestão de todas as dimensões da vida municipal, inclusive a financeira, embora tivessem que "dar no fim de cada ano conta à Representação Provincial de suas operações, na forma das leis provinciais, e publicar um balanço de receita e despesa por editais onde não houver imprensa" (p.56-57). Impunha-se a transparência, mas nada se explicitava a respeito do envio de recursos financeiros para a instância provincial. Contudo, em sentido inverso, seria possível "propor à Representação Provincial arbítrios convenientes para a construção e reparação de obras públicas quando os bens do Conselho não puderem bastar..." (p.56). 
Outra dimensão altamente valorizadora da autonomia provincial residia no entendimento da constituição e exercício da magistratura. Gonçalves Chaves propôs enfaticamente a criação de um “juiz de assembleia”, a ser eleito em "juntas ou assembleias" compostas "de todos os cidadãos residentes no distrito com exercício dos seus direitos”. Teria ele amplos poderes, exercendo "mando sobre todas as pessoas residentes em seu distrito, para o fim de toda e qualquer diligência pública ou de administração da justiça...” (p.53). Tratou-se de uma concepção que antecipou a criação, no $1^{\circ}$ Reinado, pela Câmara dos Deputados, da figura do "juiz de paz", tão cara aos liberais, inclusive aos "moderados".

Contrapondo-se à figura do magistrado de carreira, que nos municípios atuava como "juiz de fora" e tornara-se odioso por representar as instituições jurídicas do absolutismo, o pressuposto liberal era que os juízes eleitos na localidade seriam muito mais equânimes nos seus procedimentos, por conhecerem os problemas a eles afetos e estarem sob o controle da sociedade imediata. Dessa forma, argumentava o autor da memória:

Para um cargo tão honroso e importante, fica claro que só se deve eleger o cidadão de mais probidade e inteireza, mas estamos certos que o povo terá o cuidado de fazer boa eleição. Quando constar à câmara, por queixa fundada, a prevaricação ou abuso do juiz, deve ser ali chamado e se não se justificar plenamente ficará deposto e o povo nomeará outro para acabar o ano... (p.53)

Argumentava ele ainda com os gastos desnecessários com os magistrados de carreira, considerando "um absurdo de economia política nomear juízes de fora para as vilas" (p.54). Como se verificou posteriormente, a prática político-social em relação à eleição e exercício do cargo de juiz de paz ocorreu de modo muito contrário ao imaginado, dado o controle que os potentados locais tinham sobre uma população deles dependente e pouco letrada, sobretudo, nos municípios menores e/ou mais distantes das capitais provinciais (Flory, 1986; Coser, 2008).

O próprio Gonçalves Chaves, na mesma memória, incorreu em contradição a esse respeito. Ao se declarar contra a "introdução de pretos escravos no Brasil", considerou que ela deveria ser "vedada logo que nosso soberano possa impor leis...", pois "atualmente a opinião pública é a nossa lei e, por infelicidade nossa, ela não está bem formada” (p.67).

No que se refere à esfera provincial, de modo original para aquele momento, Chaves propôs a instituição de uma esfera legislativa, constituída pela 
“Câmara de Representantes Provinciais", que elaboraria uma "Constituição Provincial”, com a seguinte abrangência:

A Constituição da província regulará as atribuições do governador expressamente e se suas funções devem se repartir por mais indivíduos; a distribuição e arrecadação dos impostos, vigilância sobre os fundos públicos dos povos, o exame de suas contas; ereção de vilas, as obras públicas e distribuição de terras incultas; a educação, a moral, o culto; a agricultura, a indústria e comércio; os novos inventos, estabelecimentos de beneficência e filantropia e quaisquer objetos de pública utilidade, são da competência do governo provincial. (p.61)

No plano financeiro - lembrando que às "Representações Provinciais" caberia socorrer os municípios em caso de necessidade - nada se esclarecia sobre a origem dos recursos provinciais. Embora prevendo que haveria "arrecadação de impostos”, não se especificava a sua natureza e regularidade. Essas Câmaras teriam autonomia para decidir das leis provinciais, "e em todos os seus regulamentos serão uma perfeita imagem das Cortes Nacionais (ainda o Congresso de Lisboa). Suas leis podem denominar-se 'portarias' e serão coligidas em um livro no fim de cada legislatura e publicado por via da imprensa” (p.61).

Os posicionamentos do autor analisado absolutizavam a autonomia provincial, numa formulação que, inicialmente pensada para a monarquia portuguesa, redirecionava-se para o Brasil independente: "as funções do sumo império devem dividir-se entre soberanias entre si tão independentes que nunca se oprimam entre si, e esta é a temperança da monarquia temperada" (p.59).

As eleições e a instituição do legislativo consubstanciariam o pacto político do qual resultava a formação da nação: "Estabelecido o princípio de que a nação é soberana, segue-se que seu governo é representativo e só o pode ser pelos sufrágios do povo, que o institui para vantagem comum da sociedade... A nação de jure fica bem representada pelo método de nossas eleições, por via das quais delega seus poderes em seus deputados, formal, tácita e expressamente, e estes têm estrita obrigação de fazerem as instruções a bem dos povos..." (p.60). Concepção essa que distinguirá os projetos políticos em curso no $1^{\circ}$ Reinado, em que, entre os espectros liberais e conservadores, com ênfases variadas, se debatia a primazia da nação ou do monarca na instituição da soberania nacional (Lyra, 1995).

Num projeto em que se determinava detalhadamente como seria a eleição dos membros das câmaras municipais e da Provincial, não ficava, contudo, clara a forma por que se escolheria o governador. Embora afirmando que "a 
nomeação de um chefe ou governador da província toca inquestionavelmente aos povos da mesma província", seria este "um dos objetos que a Constituição tem a determinar". Abria-se espaço para uma indicação central, ao se afirmar que caberia à Constituição provincial determinar os vencimentos do governador, "e dos mais empregados públicos da província, ainda daqueles mesmos que devam ser nomeados pelo governo supremo" (p.61). Por sua vez, em que pesasse a força da Câmara Provincial em fiscalizar a atuação do governador, considerava Chaves entender-se "o governo da província" "equilibrado pela câmara e governador”.

No quadro de incertezas políticas então vivenciadas, entre o temor da fragmentação e a ojeriza à centralização, o empresário luso-gaúcho confessou sentir "o maior temor que se pode imaginar" em fazer propostas sobre a organização provincial. Enfatizou mais uma vez a questão do isolamento e da diversidade das províncias: "Quando meditamos na vastidão de terreno de que se compõe o Brasil, suas províncias entre si isoladas, mui diferentes raças e opiniões, variedade de caracteres em seus habitantes ... a preeminência em que estão já hoje alguns governos provinciais, e outras muitas circunstâncias que recomendamos às meditações dos políticos sensatos..." (p.58). Dessa forma, temendo a fragmentação, abria espaço para uma ação executiva, central, em relação às províncias.

No que se refere à relação entre município e província, em que pesassem as largas atribuições da Câmara Provincial, observa-se que a autonomia municipal se imporia à soberania provincial. Temática que se apresentará posteriormente no $1^{\circ}$ Reinado, tanto entre os "moderados" paulistas como em um "liberal-radical", do porte de Frei Caneca, que procuravam impor a autoridade provincial sobre os municípios. Dessa forma, os primeiros, ao mesmo tempo que formulavam modos de aceitação de um monopólio fiscal por parte do governo central, buscavam, por intermédio da ação dos seus Conselhos, disciplinar a atuação das Câmaras, obrigadas a sistematizarem os seus procedimentos de prestação de contas, e limitadas em seus poderes financeiros (Leme, 2008). Num polo oposto, Frei Caneca, negando ao governo central a constituição de finanças regulares, advogava a soberania provincial sobre os municípios, entre outros fatores, por intermédio de uma centralização financeira (Leme, 2017).

Observa-se, tanto num como noutro polo, tratar-se de uma legitimidade em construção, por parte dos respectivos governos provinciais, que estariam procurando superar o predomínio das câmaras municipais, como referido, historiograficamente vistas como as únicas instâncias político-institucionais 
com poder efetivamente reconhecido, nas diferentes dimensões espaço-territoriais da sociedade colonial. Movimento de legitimação esse ratificado pela Câmara Geral dos Deputados do Império do Brasil, com a lei de 1828, que reformou e limitou os poderes das câmaras municipais. Em 1821 e 1822, no rescaldo do ódio aos capitães gerais, Chaves reforçava o poder municipal, simultaneamente à proposta de construção de um novo tipo de poder provincial.

A originalidade da proposta do charqueador em relação à representação provincial antecipou o que veio posteriormente a ocorrer nesse sentido no Brasil independente, ao aflorar a questão da instituição de algum nível de "legislativo" provincial desde o início do $1^{\circ}$ Reinado. Dessa forma, a Assembleia Constituinte e Legislativa das Províncias do Brasil promulgou, em 20 de outubro de 1823, uma lei de organização dos governos provinciais em que, a par de um presidente indicado pelo governo central, instituía-se um Conselho de Presidência, eleito, ao qual ficava subordinada a grande maioria das decisões do presidente. Por sua vez, a Constituição de 1824 instituiu os Conselhos Gerais de Província, também eleitos, numericamente bem mais amplos do que o Conselho da Presidência, e com atribuições que incluíam a elaboração de projetos de lei provinciais, a serem submetidas à deliberação da Câmara dos Deputados. Como já referido, o empresário participou do Conselho rio-grandense. Em 1835, com o Ato Adicional, instituíram-se as Assembleias Provinciais, que permaneceram mesmo após o chamado "Regresso" centralizador (Dolhnikoff, 2005).

Qual seria, entre 1821 e 1822, a concepção do autor em análise sobre a organização de um governo central para o Brasil? Embora defendendo enfaticamente a figura real, nada explicitou a respeito, podendo-se apenas inferir alguns elementos sobre esse assunto. Tomando-se a temática dos controles fiscais e militares - aspectos fundantes da construção soberana do Estado moderno, também em sua dimensão liberal (Elias, 1993) -, infere-se uma proposta confederativa por parte de Chaves, no mesmo sentido em que se colocarão "liberais-radicais" como Frei Caneca e Cipriano Barata, já no ano de 1823, com a Constituinte reunida.

Na dimensão financeira, no modo como tratou Chaves das finanças municipais, o horizonte-limite da questão estaria nas províncias, nada restando ao nível central. No que se refere aos controles militares, o autor enfatizou as "bases da Constituição de Vermont", como "certamente a mais liberal dos Estados Unidos", proclamando-se, entre outros temas, que o "povo tem direito de ter armas, mas não haverá exércitos em tempo de paz” (p.68). 
Simultaneamente, o autor em análise referiu-se elogiosamente aos "Apontamentos do governo de São Paulo aos deputados da sua província" (para as Cortes lisboetas), indicando a sua preocupação com a unidade do Brasil e a articulação política com outras províncias, ainda que com posicionamentos mais próximos ao Rio de Janeiro, na contramão do espectro considerado "liberal-radical", do qual mais se aproximavam as suas concepções: "Não vos deixeis dominar pelo espírito dos partidos: examinai bem as circunstâncias para chegardes a um resultado que nos conduz à paz universal de toda a nação. Lede com atenção as lembranças ou apontamentos do governo de São Paulo... e tireis ideias justas das instituições que nos convêm e melhoramentos de que necessitamos" (p.101).

Articuladas às formulações políticas para o país em formação, o charqueador apresentava concepções socioeconômicas, a seguir avaliadas, no contexto da época.

\section{CONTRAdiçÕES NOS PARÂMETROS SOCIOECONÔMICOS?}

Gonçalves Chaves, apesar de possuir um plantel de escravos considerado bastante grande, foi um dos pioneiros no combate à escravidão, apresentando já em 1817 uma memória "sobre a escravatura". No espectro dos homens da Independência, alguns anos antes, portanto, da Memória contra o tráfico, de José S. Maciel da Costa, de 1821, e da Representação à Assembleia Constituinte e Legislativa, de José Bonifácio de Andrada e Silva, de 1823.

Avaliava que o tráfico deveria cessar imediatamente, argumentando que a sua abolição não afetaria o "direito de propriedade pública ou particular", tratando-se de capitais que poderiam ser canalizados para outros gêneros de comércio (Artigo IV da terceira memória). Mostrou, dessa forma, um entendimento da amplitude do valor de troca sobre o valor de uso de uma mercadoria (Marx, 1975) sendo o primeiro intercambiável por diversos gêneros, podendo se desprender de um conteúdo específico de uso. Propunha um prazo de "dezoito meses para a liquidação de seus fundos aos negociantes ou traficantes de escravos em África, sem exclusão de um só porto” (p.99).

Já seria diferente com os escravos adquiridos pelos senhores, implicando a sua libertação uma ofensa ao direito de propriedade. Expunha por isso um plano para se suprimir a escravidão de modo paulatino. Entre outros fatores, declarar-se-ia livre "todo o oriundo de cativos... logo que conte com 25 anos..." (p.100). Previa a libertação imediata dos mestiços, tratando-se da "segunda, e 
o muito, a terceira geração em que consecutivamente tenha entrado mistura da cor branca..." (p.99).

Como outros autores antiescravistas (Rocha, 1996), considerava que a "escravatura embaraça o aperfeiçoamento da população do Brasil e de seu crescimento..." Com o trabalho da agricultura quase que exclusivamente nas mãos da "classe escrava", e recusando-se a "classe livre" a "associar-se com ela em sua vida laboriosa", o que restava para a segunda era a vadiagem, pois a indústria pouco se desenvolvia, uma vez que as "produções de indústria estrangeira a tão belo mercado lhes são fáceis de obter a escambo das ricas matérias primeiras agenciadas pelos seus escravos...” (p.85). A supressão efetiva do cativeiro ocorreria quando houvesse certeza de que "nossa força física excede a da raça preta" (p.99), o que, no seu entendimento, uma vez extinto o tráfico, não demoraria a ocorrer, dado o que considerava a pouca propensão da "classe escrava" para a autorreprodução.

A argumentação de Chaves sobre os malefícios causados pela escravidão orquestrava-se com as concepções de seus precursores na matéria, que escreviam já no século XVIII (Rocha, 1996), destacando as questões morais e sobressaindo a ênfase na incompatibilidade da escravidão com a "economia política moderna”. Uma vez não remunerado pelos seus esforços, o escravo seria incapaz de bem produzir.

As contradições daqueles que eram contra a instituição do cativeiro, mas ao mesmo tempo senhores de escravos, se evidenciam nas observações de Saint-Hilaire sobre a relação do empresário com a sua escravaria, quando de sua estada junto à charqueada de Chaves:

Nas charqueadas os negros são tratados com rudeza. O Sr. Chaves, tido como um dos charqueadores mais humanos, só fala aos seus escravos com exagerada severidade, no que é imitado por sua mulher; os escravos parecem tremer diante de seus donos... Há sempre na sala um pequeno negro de 10 a 12 anos, cuja função é ir chamar os outros escravos, servir água e prestar pequenos serviços caseiros. Não conheço criatura mais infeliz que essa criança. Nunca se assenta, jamais sorri, em tempo algum brinca! ... Afirmei que nesta capitania os negros são tratados com bondade e que os brancos com eles se familiarizam, mais que em outros pontos do País. Referia-me aos escravos das estâncias, que são em pequeno número; nas charqueadas a coisa muda de figura, porque sendo os negros em grande número e cheios de vícios, trazidos da capital, torna-se necessário tratá-los com mais energia. (Saint-Hilaire, 1974, p.69, grifo nosso) 
De acordo com o acima exposto, Saint-Hilaire distinguiu a condição escrava nas estâncias de criação de gado daquela que se apresentava nas charqueadas, e em outros pontos do "país". Como bem mostrou Fernando Henrique Cardoso (1991), o desenvolvimento destas últimas, numa economia de mercado, implicou efetivamente a existência de uma escravaria aos moldes do que se dava nas plantations, o que, no entendimento do francês, justificaria o emprego de "mais energia". Mas o viajante observou também a escravidão doméstica. Era algo generalizado, como indicou; contudo, supõe-se, um elemento "mais humano", tendo escrito um arrazoado contra a escravatura, poderia em tese impedir semelhante mau trato a uma criança. O que indica as cadeias psíquicas que se desenvolviam naqueles contextos, independentemente de posicionamentos político-ideológicos.

As contradições humanistas do empresário também se observam claramente ao tratar ele das terras indígenas, num plano de reforma fundiária para o Brasil, temática da sua quarta memória, "sobre a distribuição das terras incultas". De acordo com posicionamentos que se apresentavam entre os homens da independência, nos vários matizes liberais, Chaves se contrapunha à instituição das sesmarias, que no seu entendimento haviam permitido a existência de largos trechos de terras incultas, gerando-se uma situação de pouco aproveitamento agrário, mas com terras em tese sob o domínio de um senhor. Propôs ele detalhado plano para a transformação dessa situação, com a introdução do sistema de propriedades mercantis, em que haveria a possibilidade de aquisição das terras incultas - que, transformadas em devolutas, seriam colocadas à venda pelo Estado - pelas famílias "pobres e trabalhadoras". O novo sistema impulsionaria a diversidade produtiva e a riqueza agrícola em geral.

Nesse quadro, tratou de como se lidaria com as terras indígenas em particular. Iniciou o seu raciocínio considerando que a colonização portuguesa as teria usurpado, com a progressiva ocupação dos territórios, que, no momento em que escrevia, achavam-se sob domínio privado. Mas a seguir realizou um tour de force mental para justificar a condição fundiária então atual, ratificando as terras ocupadas e cultivadas como legítimas propriedades de um sistema mercantil. Argumentando que, por serem os "nossos índios" "povos caçadores", haveria "um direito aos povos cultos", "agricultores" e/ou "manufatores", as "classes mais nobres da espécie humana" - como seria o caso dos portugueses - de "se intrometerem a seus preceptores" (p.121). Disto, porém, "se não pode derivar um direito": "temos que as colônias tinham obrigação de comprar os terrenos para seus estabelecimentos no Brasil aos povos originários e 
proprietários deles, ou fazerem com eles alguma convenção que lhes traspassasse o domínio...” (p.122).

Dessa forma, a colonização portuguesa ter-se-ia excedido no seu "direito" de conquista. O que, contudo, não anularia o direito de propriedade por esses meios obtida, pois "se a nação brasílica não foi tão justa em sua origem como o devia ser", "o erro se não pode emendar sem subversão do aperfeiçoamento da mesma natureza e retrogradação do melhoramento da espécie humana..." (p.122).

Num contexto em que, durante o século XIX, os indígenas brasileiros foram vítimas de uma espoliação que, em nome do mercado, subordinava-os como mão de obra ou arrebatava-lhes as terras (Sampaio, 2009; Cunha, 1992), no pensamento de Chaves imperava a importância do crescimento das propriedades. Para ele, seria legítima a expansão para as áreas indígenas ainda não contatadas, mediante compra das terras a serem ocupadas, numa formulação que, simultaneamente, reconhecia os "direitos" dos indígenas e desqualificava a sua capacidade de lidar adequadamente com os valores de mercado:

temos obrigação e possibilidade de respeitar os direitos dos aborígenes que ainda existem em muitas matas do Brasil... são bárbaros, é verdade, e como tais malfeitores, ainda que algumas vezes provocados por injustiças nossas; mas nós, como mais civilizados, devemos adoçar seus costumes por nossa conduta ajustada à sã moral. Quando precisarmos de suas terras, tanto para estradas ou outras obras públicas e agricultura, devemos a comprar a preço das coisas em que com eles convencionarmos, e nunca espoliá-los; eles, que não conhecem a agricultura, não exigem grande preço. (p.122)

\section{VALORES ILUSTRADO-LIBERAIS, COMPATIBILIDADES ECONÔMICAS E PROJETOS POLÍTICO-INSTITUCIONAIS}

Os elementos que se podem analisar como contradições humanistas do autor das memórias em avaliação correspondem às contradições inerentes à própria gênese das formulações iluministas e liberais. Gonçalves Chaves escrevia num campo da compreensão da ação humana centrada nas virtudes e no direito natural, como concebidas em decorrência do nascente capitalismo, no transcorrer da chamada Idade Moderna, em particular, no século XVIII (Pocock, 2003). Afirmava a premiação do mérito em detrimento dos valores aristocráticos, a ferrenha defesa da propriedade privada e, nessa esfera, dos 
direitos individuais. No seu entendimento, "a virtude é a maior recompensa do homem".

No quadro político decorrente da Revolução do Porto, considerava que seriam necessárias "todas as virtudes públicas e particulares para vencer o espaço que vai do estado de cativeiro e aviltamento, em que jazíamos, ao estado de liberdade e glória a que aspiramos por direito" (p.49). As "memórias" em análise - expondo em livro um projeto de organização para o Estado liberal que então se formava, numa proposta de transformação das bases socioeconômicas coloniais - constituíram um trabalho intelectual pioneiro para o Brasil e a província de São Pedro da época. ${ }^{10}$

De acordo com o seu autor, a economia política seria o principal guia para a organização social, que, na sua versão, dividiria "a espécie humana em quatro distintas classes principais", em hierarquia de superioridade: os "povos caçadores", "pastores", "agricultores" e "manufatores”. Cabe lembrar, a charqueada seria uma "manufatura". Porém, pela sua exposição, embora instasse por um desenvolvimento de indústrias, constata-se que o Rio Grande do Sul estaria entre os povos "pastores" e "agricultores". Gonçalves Chaves revelou uma concepção fisiocrata, no sentido do antimetalismo como valor econômico, ao condenar o incentivo à mineração no Brasil, apresentado nos Apontamentos do governo de São Paulo. Considerou que nas

nossas circunstâncias atuais tal projeto seria inteiramente ruinoso à nossa economia política no Brasil e particularmente nesta província (RS), onde só a criação dos gados e agricultura... é que são nossas minas, sobre que devemos basear nossa prosperidade pública: reservemo-nos à exploração das minas de ouro para quando nosso comércio interior e indústria nos ofereçam um sustentáculo e emprego ao nosso numerário. (Chaves, 2004, p.156)

Mas apontou haver "outros minerais na província, tais como salitre em abundância, carvão de pedra, ferro magnete... que se devem explorar à proporção que a grandeza de nossas cidades do interior, aperfeiçoamento da navegação de nossos caudalosos rios, e fábricas de pólvora e outras proporcionem o consumo" (p.157). Defendeu ardorosamente a elaboração de detalhadas estatísticas socioeconômicas como meio da aplicação de adequadas políticas de governo, instando que a sua elaboração se tornasse obrigatória pelas províncias. No plano da economia política liberal, a partir da valorização do mundo agropastoril existente, apresentava uma expectativa de futuro fabril (Koselleck, 2006). 
No plano dos valores sociopolíticos, explicitou a diferenciação liberal entre "igualdade individual" e "igualdade política, civil ou social". A primeira constituiria "uma quimera", pois "um indivíduo não pode ser igual ao outro indivíduo em forças, em entendimento, estatura e cabedais, porquanto a mesma distribuição que a natureza faz das nossas faculdades físicas e morais nos conduza a aumentarmos, uns mais bens do que outros..." (p.72). Já outra era a concepção da "igualdade civil ou de direitos":

A esta igualdade aspiram todos os membros de todas as associações imagináveis e de direito lhes toca: ela é efetuada pela justiça e retidão das leis e sua exata observância... Em uma sociedade onde imperam leis imparciais, diz-se com razão que todos são iguais, porque todos os cidadãos são elevados aos mais vantajosos empregos somente por suas virtudes e não por nascimento ou riqueza. Os cidadãos que mais se avantajam em cabedais concorrem gostoso a oferecer grandes dons ao governo, que os despende em proveito comum da sociedade e dos membros mais necessitados especialmente... Nessa ação majestosa da concorrência de dons funda-se a verdadeira honra nacional ou patriotismo: as medalhas honoríficas derivadas das Ordens de Cavalaria são bagatelas ou restos de barbaridade romanesca... (Chaves, 2004, p.73)

Inspirado nesses princípios ilustrado-liberais, Gonçalves Chaves avançou posicionamentos sobre a organização do Estado que se podem alinhar no campo denominado "liberal-radical". Como exposto, priorizou o município e a província, elaborou um entendimento próprio da monarquia "federativa", priorizou o Legislativo sobre o Executivo, o "povo" como constituinte da nação, e negou a existência de um exército regular.

No que diz respeito à organização socioeconômica do país em formação, evidencia-se nos escritos do empresário uma concepção de sociedade hierarquizada de acordo com os valores liberais. Condenava a aristocracia e a sociedade colonial de Antigo Regime, ao mesmo tempo que distinguia as camadas que deveriam ser valorizadas na nova sociedade, condenando a "plebe" e enaltecendo os diferentes segmentos do "povo", de acordo com o mérito do seu desempenho junto ao mercado. Estabelecia-se assim uma hierarquia, em cujo topo se situavam os fazendeiros, empresários e capitalistas. Da mesma forma como pensavam, nesse sentido, outros personagens do espectro político liberal que se desenvolvia no Brasil no período da Independência e construção do $1^{\circ}$ Reinado, quer se tratasse de elementos adeptos da centralização, classificados como conservadores, tal qual José Bonifácio, também um antiescravista, ou 
daqueles denominados "liberais-radicais", que não se opuseram claramente à escravidão, como Frei Caneca (Gil, 2002).

\section{REFERENCIAS}

BARRETO, Abeillard. Bibliografia sul-riograndense: a contribuição portuguesa e estrangeira para o conhecimento do Rio Grande do Sul. Rio de Janeiro: Conselho Federal de Cultura, 1973.

BERUTE, Gabriel S. Atividades mercantis do Rio Grande de São Pedro: negócios, mercadorias e agentes mercantis. Tese (Doutorado em História) - Universidade Federal do Rio Grande do Sul (UFRGS). Porto Alegre, 2011.

CARDOSO, Fernando H. Capitalismo e Escravidão no Brasil Meridional. 3.ed. Rio de Janeiro: Paz e Terra, 1991.

CHAVES, Antônio José G. Memórias ecônomo-políticas sobre a administração pública do Brasil. (1822-1823). 4.ed. São Leopoldo, RS: Ed. Unisinos, 2004.

COSER, Ivo. Visconde do Uruguai: centralização e federalismo no Brasil 1823-1866. Belo Horizonte: Ed. UFMG; Rio de Janeiro: Iuperj, 2008. Cap. 4: “Civilização e sertão".

CUNHA, Manuela C. da (Org.) Política indigenista no século XIX. In: História dos índios no Brasil. São Paulo: Companhia das Letras; Secretaria Municipal de Cultura; Fapesp, 1992.

CUNHA, Pedro Octavio C. da. A fundação de um império liberal. In: HOLANDA, Sérgio Buarque de. O Brasil Monárquico. Tomo II, vol. 1: O processo de emancipação. 6.ed. São Paulo: Difel, 1985. p.135-178.

DOLHNIKOFF, Miriam. O pacto imperial: origens do federalismo no Brasil. São Paulo: Globo, 2005.

ELIAS, Norbert. O Processo Civilizador. vol. 2: Formação do Estado e civilização. Rio de Janeiro: Jorge Zahar, 1993.

FLORY, Thomas. El juez de paz y el jurado en el Brasil imperial. México: Fundo de Cultura Económica, 1986.

FRANCO, Sérgio da C. Notícia bio-bibliográfica. In: CHAVES, Antônio José G. Memórias ecônomo-políticas sobre a administração pública do Brasil: entendimentos federativos e sociedade de mercado. 4.ed. São Leopoldo, RS: Ed. Unisinos, 2004.

GELDEREN, Martin van; SKINNER, Quentin (Ed.) Republicanism: A Shared Republican Heritage. vol. I: Republicanism and Constitutionalism in Early Modern Europe. vol. II: The Values of Republicanism in Early Modern Europe. Cambridge, UK: Cambridge University Press, 2002. 
GIL, Antonio Carlos A. Projetos de Estado no alvorecer do Império: Sentinela da Liberdade e Typhis Pernambucano: a formulação de um projeto de construção do Estado. Vitória: IHGES, 2002.

GORENSTEIN, Riva. Comércio e política: o enraizamento de interesses mercantis portugueses no Rio de Janeiro (1808-1830). In: MARTINHO, Lenira M.; GORENSTEIN, R. Negociantes e caixeiros na sociedade da Independência. Rio de Janeiro: Secretaria Municipal de Cultura, Turismo e Esportes, 1993. p.129-222. (Biblioteca Carioca).

GOUVÊA, Maria de Fátima S. Poder político e administração na formação do complexo atlântico português. In: FRAGOSO, João; BICALHO, Maria Fernanda B.; GOUVÊA, Maria de Fátima S. (Org.) O Antigo Regime nos trópicos: a dinâmica imperial portuguesa (séculos XVI-XVIII). Rio de Janeiro: Civilização Brasileira, 2001.

KOSELLECK, Reinhart. Futuro passado: contribuição à semântica dos tempos históricos. Rio de Janeiro: Contraponto; Ed. PUC-Rio, 2006.

LEME, Marisa Saenz. Dinâmicas centrípetas e centrífugas na formação do Estado monárquico no Brasil: o papel do Conselho Geral da Província de São Paulo. Revista Brasileira de História, São Paulo: Anpuh, v.28, n.55, p.197-215, 2008.

Federalismo e posturas confederativas no discurso político do Brasil independente: as concepções dos escritos de Frei Caneca. Almanack, Guarulhos: Unifesp, v.15, p.214-244, 2017. Disponível em: http://www.scielo.br/scielo. php?pid=S2236-46332017000100183\&script=sci_arttext\&tlng=pt.

LIMA, Manuel de O. O Movimento da Independência (1820-1822). Belo Horizonte: Itatiaia; São Paulo: Edusp, 1989.

LYRA, Maria de Lourdes V. Memória da Independência: marcos e representações simbólicas. Revista Brasileira de História, São Paulo: Anpuh, v.15, n.29, p.173-206, 1995. (Dossiê: Representações).

. Pátria do cidadão: a concepção de pátria/nação em Frei Caneca. Revista Brasileira de História, São Paulo: Anpuh, v.18, n.36, 1998. (Dossiê: Do Império Português ao Império do Brasil). Disponível em: http://www.scielo.br/scielo. php?script=sci_arttext\&pid=S0102-01881998000200016.

MARX, Karl. O Capital: crítica da economia política. Livro Primeiro: O processo de produção do capital. vol. I. 3.ed. Rio de Janeiro: Civilização Brasileira, 1975.

MENZ, Maximiliano. Entre impérios: formação do Rio Grande na Crise do Sistema Colonial Português (1777-1822). São Paulo: Alameda, 2009.

MIRANDA, Márcia E. A estalagem e o Império: crise do Antigo Regime, fiscalidade e fronteira na província de São Pedro (1808-1831). Tese (Doutorado em Economia) - Universidade Estadual de Campinas (Unicamp). Campinas, 2006.

NEVES, Lucia Maria B. P. das. Corcundas e constitucionais: a cultura política da Independência (1820-1822). Rio de Janeiro: Revan; Faperj, 2003. 
OLIVEIRA, Cecilia Helena de S. A Astúcia Liberal: relações de mercado e projetos políticos no Rio de Janeiro (1820-1824). Bragança Paulista, SP: Edusf; Ícone, 1999. POCOCK, John G. A. Linguagens do ideário político. São Paulo: Edusp, 2003.

ROCHA, Antonio P. A economia política na sociedade escravista. São Paulo: Hucitec, 1996.

RUSSELL-WOOD, John R. O governo local na América portuguesa: um estudo de divergência cultural. In: Histórias do Atlântico português. São Paulo: Ed. Unesp, 2014.

SAINT-HILAIRE, Auguste de. Viagem ao Rio Grande do Sul, 1820-1821. Belo Horizonte: Itatiaia; São Paulo: Edusp, 1974.

SAMPAIO, Patrícia de M. Política indigenista no Brasil Imperial. In: GRINBERG, Keila; SALES, Ricardo (Org.) O Brasil Imperial (1808-1831). vol. 1. Rio de Janeiro: Civilização Brasileira, 2009.

SANTOS, Corcino M. dos. Economia e sociedade no Rio Grande do Sul: século XVIII. São Paulo: Cia. Ed. Nacional; Brasília: INL, 1984.

SOUZA, Iara Lis Carvalho. Pátria Coroada: o Brasil como Corpo Político Autônomo (1780-1831). São Paulo: Ed. Unesp, 1999.

TAVARES, Luís Henrique D. A Independência do Brasil na Bahia. Rio e Janeiro: Civilização Brasileira; Brasília: INL, 1977.

\section{NOTAS}

${ }^{1}$ A viagem seguiu, contudo, até junho de 1821 , consistindo o texto, segundo o seu editor, R. de Dreuzy, uma "espécie de inventário", resultante do "diário redigido a cada noite durante penosa exploração na Província do Rio Grande do Sul, prosseguida até Montevidéu..." (SAINT-HILAIRE, 1974, p.16).

${ }^{2}$ Pelotas foi elevada à categoria de vila em 1832.

${ }^{3}$ Em que pese o anonimato, "não existe dúvida" quanto à sua identidade (FRANCO, 2004, p.17).

${ }^{4}$ Dadas as suas especificidades, não relevantes para os objetivos do presente texto, essa memória não foi comentada.

${ }^{5}$ Conforme explicitado na página de rosto: "Tudo quanto tratamos nas cinco memórias que nos dispomos a escrever, temos por matérias urgentes para se tratarem nas Cortes logo que cheguem nossos deputados, e se não bem desempenhadas, ao menos estimularão melhores engenhos, e já assim somos contentes" (CHAVES, 1822, p.2, grifo nosso).

${ }^{6}$ Embora variando as perspectivas analíticas, o acontecimento é assim reconhecido por autores de diferentes inserções historiográficas. Para tanto, ver, entre outros: CUNHA, 1985; LIMA, 1989; NEVES, 2003; OLIVEIRA, 1999. 
${ }^{7}$ As Memorias tiveram uma segunda edição em 1922, feita pelo IHGRS; uma terceira, em 1978, pela União de Seguros Gerais, de Porto Alegre; e a quarta, em 2004, pela Editora Unisinos.

${ }^{8} \mathrm{~A}$ ideia da "monarquia federativa", em vários momentos adotada por Cipriano Barata, foi nessa matéria claramente apresentada nas suas dimensões confederativas.

${ }^{9}$ Cabe lembrar que a convocação da Constituinte em 3 de junho de 1822 se deu ainda no âmbito da união com Portugal.

${ }^{10}$ Observe-se que a imprensa, embora bastante atuante entre 1821 e 1822, no Rio de Janeiro e no então Norte - dada a liberdade advinda com a Revolução do Porto - só se desenvolverá nas regiões Centro-Sul durante o $1^{\circ}$ Reinado. Foram raras as publicações de livros com o teor das "Memórias" ora analisadas.

Artigo recebido em $1^{\circ}$ de novembro de 2017.

Aprovado em 6 de fevereiro de 2018. 